\title{
SYNTHESIS, CHARACTERIZATION AND THERMAL STUDIES OF MIXED LIGAND COMPLEXES OF Hg(II) THIOSEMICARBAZONES WITH 2-AMINOTHIAZOLE
}

\author{
Kamal S. T. Al-Jadabi* \\ Department of Chemistry, Faculty of Education-Arhab, Sana'a University, Sana'a, Yemen

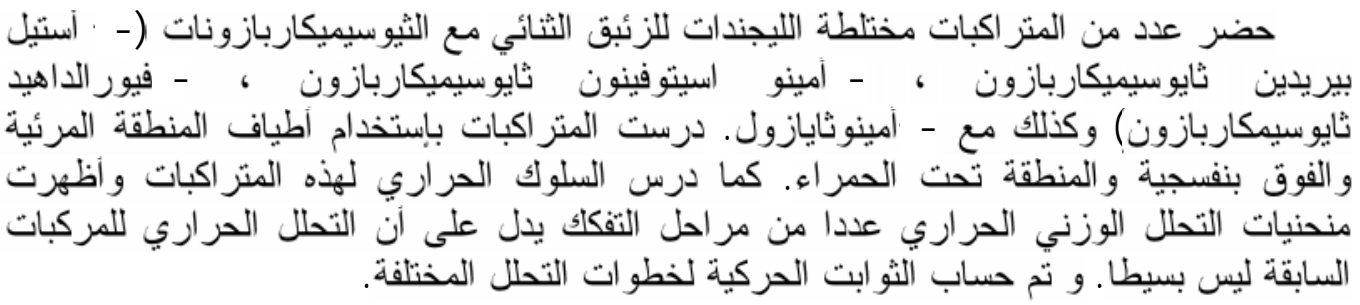

Several Hg(II) mixed ligand complexes of thiosemicarbazones (2-acetylpyridine-, 4aminoacetophenone- and 2-furaldehyde thiosemicarbazones) with 2-aminothiazole have been prepared. Structural investigations of the complexes have been made based on elemental analyses, spectral (UV-Vis, IR) studies and conductivity measurements. The I.R. spectra indicated the bidentate (neutral) behaviour of the ligands. The thermogravimetry (TG), derivative thermogravimetry (DTG) and differential thermal analyses (DTA) have been used to study the thermal decomposition and kinetic parameters of the complexes using the CoastsRedfern and Horowitz-Metzger equations.

\section{INTRODUCTION}

Thiosemicarbazones and their metal complexes have been a subject of interest in numerous studies because of their chemical and biological activities ${ }^{1 \& 2}$. They have a wide range of beneficial medicinal properties ${ }^{3 \& 4}$ that are often attributed to their chelating ability with metal ions ${ }^{5}$. Really, an important number of thiosemicarbazones being NNS tridentate donors and possess carcinostatic efficacy ${ }^{6}$, and substantial in-vivo activity against various human tumors ${ }^{7 \& 8}$. However, structural variations in some thiosemicarbazones with regard to their chelating ability may destroy or reduce their medicinal values'.

$\mathrm{Hg}$ (II) complexes of benzophenone, acetophenone and salicylaldehyde thiosemicarbazones containing the neutral or anionic form of these ligands were prepared and fully characterized ${ }^{10}$.

The present work gives an insight about the preparation, spectral characterization and thermal studies of $\mathrm{Hg}(\mathrm{II})$ mixed ligand complexes of thiosemicarbazones (2-acetyl- pyridine-, 4-aminoacetophenone- and 2furaldehyde-thiosemicarbazones) (HPTSC, HTASC and HFTSC respectively) with 2aminothiazole (AZ) (Fig. 1). The kinetic and thermodynamic parameters for some thermal decomposition steps have been studied.

\section{EXPERIMAENTAL}

All chemicals used were of analytical reagent grade (Merck or BDH).

\section{Preparation of thiosemicarbazone ligands}

The thiosemicarbazone ligands used in this study were prepared according to published procedures ${ }^{11}$ as follows:

2-Acetylpyridine thiosemicarbazone (HPTSC), 4-aminoacetophenone thiosemicarbazone (HATSC) and 2-furaldehyde thiosemicarbazone (HFTSC) were prepared by mixing an ethanolic solution $(20 \mathrm{ml})$ of 2acetylpyridine, 4-aminoacetophenone or 2furaldehyde $(2 \mathrm{mmol})$ with $20 \mathrm{ml}$ of an ethanolic solution of thiosemicarbazide (2 mmol). The mixture was stirred for $5 \mathrm{~min}$. and 
<smiles>C/C(=N\NC(N)=S)c1ccccn1</smiles>

HPTSC

(2-acetylpyridinethiosemicrbazone) $\left(\mathrm{C}_{8} \mathrm{H}_{10} \mathrm{~N}_{4} \mathrm{~S}\right)$<smiles>C/C(=N\NC(N)=S)c1ccc(N)cc1</smiles>

HATSC

(4-aminoacetophenonethiosemicarbazone) $\left(\mathrm{C}_{9} \mathrm{H}_{12} \mathrm{~N}_{4} \mathrm{~S}\right)$<smiles>NC(=S)N/N=C/c1ccco1</smiles>

HFTSC

(2-furaldehydethiosemicarbazone)

$\left(\mathrm{C}_{6} \mathrm{H}_{7} \mathrm{~N}_{3} \mathrm{OS}\right)$<smiles>Nc1nccs1</smiles>

AZ

(2-aminothiazole) $\left(\mathrm{C}_{3} \mathrm{H}_{4} \mathrm{~N}_{2} \mathrm{~S}\right)$

Fig. 1: The structures of the studied thiosemicarbazones and 2-aminothiazole.

then heated on a water bath for $10 \mathrm{~min}$. whereupon the ligands precipitated immediately. The separated compounds were filtered, washed with ethanol and finally dried over anhydrous calcium chloride. The proposed chemical structure of the prepared thiosemicarbazone ligands are in good agreement with the stoichiometric concluded from their analytical data (Table 1) and confirmed from the IR spectral data (Table 2).

\section{Preparation of $\mathrm{Hg}(\mathrm{II})$ mixed ligand complexes}

The $\mathrm{Hg}$ (II) mixed ligand complexes of thiosemicarbazones with 2-aminothiazole were prepared by mixing a hot ethanolic solution (20 $\mathrm{ml})$ of the respective thiosemicarbazones (HPTSC or HATSC or HFTSC) $(2 \mathrm{mmol})$ with an ethanolic solution $(10 \mathrm{ml})$ of 2aminothiazole $(2 \mathrm{mmol})$. To this solution was added with constant stirring a hot ethanolic solution $(20 \mathrm{ml})$ of $\mathrm{HgCl}_{2}(1 \mathrm{mmol})$. The mixture was heated under reflux for $30 \mathrm{~min}$, cooled and left overnight, microcrystalline products were separated thoroughly washed with ethanol and dried in air.

\section{Analysis and physical measurements}

CHNS analyses were preformed using Elementar-Analyses system $\mathrm{GmbH}$ Vario El analyzer at the Microanalytical unit of Assiut University. Infrared spectra were recorded on a 470 Shimadzu infrared spectrophoto- meter as $\mathrm{KBr}$ disks at room temperature. The electronic spectra were measured in DMF solutions on a Perkin Elmer, Lambda 35 UV/VIS spectrophotometer. Electrical conductivity of $10^{-4} \mathrm{M}$ solution of the complexes were measured at room temperature on a Jenway 4330 conductivity meter. Thermogravimetric (TG) and differential thermal analyses (DTA) of the solid complexes were done using a DTG$60 \mathrm{H}$ thermogravimetric analyser (Shimadzu). TG/DTA measurements were run under dynamic air at a heating rate $10^{\circ} \mathrm{C} \min ^{-1}$ and between ambient temperature $750^{\circ} \mathrm{C}$.

\section{RESULTS AND DISCUSSION}

The isolated complexes are stable in air, insoluble in water and common organic solvents, but completely soluble in DMF and DMSO.

The reaction of $\mathrm{Hg}$ (II) chloride with the thiosemicarbazone and 2-aminothiazole ligands is illustrated in equation (1).

$\mathrm{HgCl}_{2}+2 \mathrm{HTSC}+\mathrm{AZ} \longrightarrow\left[\mathrm{Hg}(\mathrm{HTSC})_{2} \mathrm{AZ} \mathrm{Cl}_{2}\right.$

(where $\mathrm{HTSC}=$ thiosemicarbazone and $\mathrm{AZ}=2$ aminothiazole)

Table 1 includes the physical and elemental analyses of the thiosemicarbazones and their corresponding complexes.

\section{Molar conductance}

Molar conductance measurements of $10^{-4}$ $\mathrm{M}$ solutions of the complexes in DMF are in the range 139.2-156.4 $\mathrm{Ohm}^{-1} \mathrm{~cm}^{2} \mathrm{~mol}^{-1}$ for all complexes indicating their neutral electrolytic nature of the complexes ${ }^{12}$. 
Table 1: Physical properties and elemental analysis of the thiosemicarbazones and $\mathrm{Hg}$ (II) mixed ligand complexes.

\begin{tabular}{|c|c|c|c|c|c|c|c|}
\hline \multirow{2}{*}{$\begin{array}{l}\text { Thiosemicarbazones } \\
\text { and complex }\end{array}$} & \multirow{2}{*}{$\begin{array}{c}\text { M.F } \\
\text { (M. Wt) }\end{array}$} & \multirow{2}{*}{ Colour } & \multirow{2}{*}{$\begin{array}{c}\text { m.p. } /{ }^{\circ} \mathrm{C} \\
\text { (Decomp) }\end{array}$} & \multicolumn{4}{|c|}{ Found / (Calc.) } \\
\hline & & & & $\mathrm{C} \%$ & $\mathrm{H} \%$ & $\mathrm{~N} \%$ & $\mathrm{~S} \%$ \\
\hline HPTSC & $\begin{array}{c}\mathrm{C}_{8} \mathrm{H}_{10} \mathrm{~N}_{4} \mathrm{~S} \\
(194.18)\end{array}$ & $\begin{array}{l}\text { Light } \\
\text { Brown }\end{array}$ & 139 & $\begin{array}{c}49.62 \\
(49.44)\end{array}$ & $\begin{array}{c}5.12 \\
(5.15)\end{array}$ & $\begin{array}{c}28.51 \\
(28.84)\end{array}$ & $\begin{array}{c}16.67 \\
(16.48)\end{array}$ \\
\hline HATSC & $\begin{array}{c}\mathrm{C}_{9} \mathrm{H}_{12} \mathrm{~N}_{4} \mathrm{~S} \\
(208.18)\end{array}$ & $\begin{array}{l}\text { Light } \\
\text { Brown }\end{array}$ & 141 & $\begin{array}{c}51.54 \\
(51.88) \\
\end{array}$ & $\begin{array}{c}5.72 \\
(5.76) \\
\end{array}$ & $\begin{array}{l}26.78 \\
(26.90) \\
\end{array}$ & $\begin{array}{l}15.19 \\
(15.37) \\
\end{array}$ \\
\hline HFTSC & $\begin{array}{c}\mathrm{C}_{6} \mathrm{H}_{7} \mathrm{~N}_{3} \mathrm{OS} \\
(169.15)\end{array}$ & $\begin{array}{l}\text { Light } \\
\text { Brown }\end{array}$ & 132 & $\begin{array}{c}42.11 \\
(42.57)\end{array}$ & $\begin{array}{c}4.23 \\
(4.14)\end{array}$ & $\begin{array}{c}24.97 \\
(24.83)\end{array}$ & $\begin{array}{c}19.13 \\
(18.92)\end{array}$ \\
\hline$\left[\mathrm{Hg}(\mathrm{HPTSC})_{2}(\mathrm{AZ})_{2}\right] \mathrm{Cl}_{2}$ & $\begin{array}{c}\mathrm{C}_{22} \mathrm{H}_{28} \mathrm{Cl}_{2} \mathrm{HgN}_{12} \mathrm{~S}_{4} \\
(860.23)\end{array}$ & Yellow & 261 & $\begin{array}{c}30.80 \\
(30.91) \\
\end{array}$ & $\begin{array}{c}2.56 \\
(2.71) \\
\end{array}$ & $\begin{array}{c}19.53 \\
(19.31)\end{array}$ & $\begin{array}{r}14.90 \\
(14.76) \\
\end{array}$ \\
\hline$\left[\mathrm{Hg}(\mathrm{HATSC})_{2}(\mathrm{AZ})_{2}\right] \mathrm{Cl}_{2}$ & $\begin{array}{c}\mathrm{C}_{24} \mathrm{H}_{23} \mathrm{Cl}_{2} \mathrm{HgN}_{12} \mathrm{~S}_{4} \\
(888.24)\end{array}$ & Yellow & 275 & $\begin{array}{c}32.42 \\
(31.73)\end{array}$ & $\begin{array}{c}3.60 \\
(3.52)\end{array}$ & $\begin{array}{c}18.91 \\
(18.46)\end{array}$ & $\begin{array}{c}14.41 \\
(14.23)\end{array}$ \\
\hline$\left[\mathrm{Hg}(\mathrm{HFTSC})_{2}(\mathrm{AZ})_{2}\right] \mathrm{Cl}_{2}$ & $\begin{array}{c}\mathrm{C}_{18} \mathrm{H}_{22} \mathrm{Cl}_{2} \mathrm{HgN}_{10} \mathrm{~S}_{4} \\
(810.19)\end{array}$ & Yellow & 252 & $\begin{array}{l}26.67 \\
(27.11)\end{array}$ & $\begin{array}{l}2.72 \\
(2.84)\end{array}$ & $\begin{array}{c}17.28 \\
(17.36)\end{array}$ & $\begin{array}{c}15.80 \\
(15.93)\end{array}$ \\
\hline
\end{tabular}

Table 2: IR spectral data $\left(\mathrm{cm}^{-1}\right)$ of free thiosemicarbazones and $\mathrm{Hg}(\mathrm{II})$ mixed ligand complexes.

\begin{tabular}{||c|c|c|c|c|c|}
\hline Complex & $v\left(\mathrm{NH} / \mathrm{NH}_{2}\right)$ & $v(\mathrm{C}=\mathrm{N})$ & $v(\mathrm{C}=\mathrm{S})$ & $v(\mathrm{C}-\mathrm{S})$ & $v(\mathrm{M}-\mathrm{N})$ \\
\hline $\begin{array}{c}\text { Free thiosemicarbazones, } \\
\text { 2-aminothiazole }\end{array}$ & $3220-3450 \mathrm{~m}$ & $1600 \mathrm{~s}$ & $830 \mathrm{~s}$ & - & - \\
\hline$\left[\mathrm{Hg}(\mathrm{HPTSC})_{2}(\mathrm{AZ})_{2}\right] \mathrm{Cl}_{2}$ & $3110-3420 \mathrm{~m}$ & $1590 \mathrm{~s}$ & $820 \mathrm{~s}$ & $690 \mathrm{~s}$ & $450 \mathrm{~s}$ \\
\hline$\left[\mathrm{Hg}(\mathrm{HATSC})_{2}(\mathrm{AZ})_{2}\right] \mathrm{Cl}_{2}$ & $3220-3440 \mathrm{~m}$ & $1585 \mathrm{~s}$ & $790 \mathrm{~s}$ & $690 \mathrm{~s}$ & $440 \mathrm{~s}$ \\
\hline$\left[\mathrm{Hg}(\mathrm{HFTSC})_{2}(\mathrm{AZ})_{2}\right] \mathrm{Cl}_{2}$ & $3250-3400 \mathrm{~m}$ & $1580 \mathrm{~m}$ & $785 \mathrm{~m}$ & $695 \mathrm{~s}$ & $455 \mathrm{~s}$ \\
\hline
\end{tabular}

$\mathrm{s}=$ strong

$\mathrm{m}=$ medium

\section{IR Spectra}

The most characteristic bands of the free ligands and complexes are summarized in Table 2. A representative example for their spectra is given in Figure 2.

The coordination sites of the ligands under investigation with $\mathrm{Hg}(\mathrm{II})$ ions were elucidated using IR spectra. The data obtained suggest that the thiosemicarbazone ligands bind to the metal ions in a bidentate fastion and coordinate through the $\mathrm{C}=\mathrm{N}$ and $\mathrm{C}=\mathrm{S}$ groups. This was suggested because of the shift of $v(C=N)$ and $v(C=S)$ of the complexes to a lower frequency by $10-20$ and $10-45 \mathrm{~cm}^{-1}$, respectively, compared to the thiosemicarbazones ${ }^{13-20}$. The complexes exhibit an additional band in the region 1350-1380 $\mathrm{cm}^{-1}$ which can be assigned to $v(\mathrm{C}-\mathrm{N})$ and gives a positive shift if compared with that of the free 2-aminothiazole $\left(1322 \mathrm{~cm}^{-1}\right)^{21}$. This is an evidence in favour of bonding through amino nitrogen of the 2aminothiazole due to polarization of the $\pi-\pi$ electrons after coordination from the thiazole ring towards the nitrogen atom of the amino group. This will increase the double-bond character of $\mathrm{C}-\mathrm{N}$ in the $\mathrm{C}-\mathrm{NH}_{2}$ group, thus giving rise to the positive shift ${ }^{21}$. A band at 695 $\mathrm{cm}^{-1}$ (vC-S) of the complexes occurs at almost the same frequency as that of free 2aminothiazole $\left(690 \mathrm{~cm}^{-1}\right)$, which may rule out the possibility of coordination through the ring sulphur $^{21}$. Having concluded that the site of binding in 2-aminothiazole is exocyclic nitrogen one may ask why the site is amino nitrogen and not the nitrogen or sulfur of the ring. One possible reason for this might be that the lone pair electrons on the nitrogen of the amino group are more exposed whereas those present on the ring nitrogen or sulphur are sterically hindered by the presence of the amino group at the 2-position, thus favouring the coordination through the exocyclic nitrogen $^{21}$. Observation of a band in the region $3220-3450 \mathrm{~cm}^{-1}$ indicates the existence of 


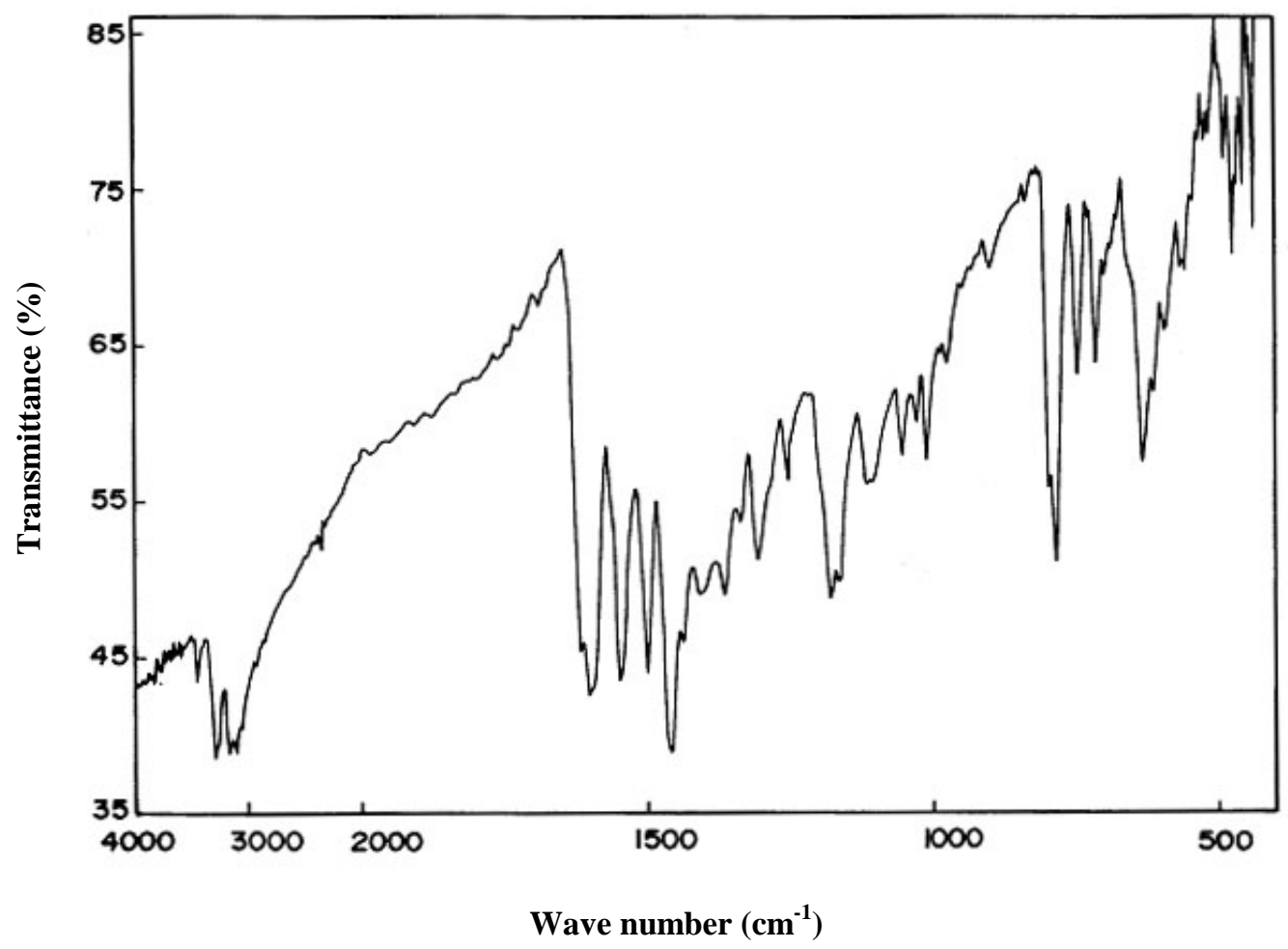

Fig. 2: IR spectrum of $\left[\mathrm{Hg}(\mathrm{HPTSC})_{2}(\mathrm{AZ})_{2}\right] \mathrm{Cl}_{2}$.

$v(\mathrm{NH}) /\left(\mathrm{NH}_{2}\right)$ of the thiosemicarbazones and 2aminothiazole ligands ${ }^{22-32}$ compared with that the complexes $\left(3110-3340 \mathrm{~cm}^{-1}\right)$. This coordination is confirmed by the presence of a new band at $430-455 \mathrm{~cm}^{-1}$ which is assigned to the stretching frequency of metal-nitrogen $v(\mathrm{M}-\mathrm{N})$ for all the complexes ${ }^{33-35}$.

\section{Electronic spectra}

The electronic spectra of these complexes, were recorded in DMF solution, have a great similarity and showed two main broad bands centered at 37, 468-32, 751 and 29, 421-25, $629 \mathrm{~cm}^{-1}$, which can be ascribed to $\pi-\pi^{*}$ and intraligand charge transfer transitions, respectively ${ }^{36-41}$. The electronic spectral bands of the complexes are summarized in Table 3.

\section{Thermal studies}

\section{a- Thermal behaviour}

The thermal behaviour of the $\mathrm{Hg}$ (II) complexes under investigation was studied in dynamic air using thermogravimetric analysis (TGA), derivatives thermogravimety (DTG) and differential thermal analysis (DTA). The thermal decomposition of the complexes was recorded from ambient temperature to $750^{\circ} \mathrm{C}$
(Table 4). The results showed that the complexes generally decomposed in several thermal events, i.e., three or five decomposition steps. The first step for all complexes represents a dehydration step which correlates well with the theoretical values corresponding to the elimination of $2 \mathrm{HCl}$ molecules present. The end products of the decomposition were identified from the $\mathrm{TG}$ traces to be $\mathrm{HgO}$.

The thermal decomposition of $\left[\mathrm{Hg}(\operatorname{HATSC})_{2}(\mathrm{AZ})_{2}\right] \mathrm{Cl}_{2}$ is depicted in Figure 3 , as a typical example for the decomposition of these compounds. The decomposition of $\left[\mathrm{Hg}(\mathrm{HATSC})_{2}(\mathrm{AZ})_{2}\right] \mathrm{Cl}_{2}$ proceeds in three steps in the temperature ranges 140-277, 278-409 and $410-682^{\circ} \mathrm{C}$. The complex is stable up to $140^{\circ} \mathrm{C}$, then started to decompose at a temperature above this limit. The observed mass loss of the first step agreed with the loss of $2 \mathrm{HCl}$ molecules (calc. $8.2 \%$, found $8.4 \%$ ) due to deprotonation of thiosemicarbazone ligand (DTG peak at $248^{\circ} \mathrm{C}$ ), for which an endothermal appears in the DTA curve at $241^{\circ} \mathrm{C}$ (equation 2).

$$
\begin{gathered}
{\left[\mathrm{Hg}(\mathrm{HATSC})_{2}(\mathrm{AZ})_{2}\right] \mathrm{Cl}_{2} \stackrel{140-277^{\circ} \mathrm{C}}{\longrightarrow}} \\
{\left[\mathrm{Hg}(\mathrm{ATSC})_{2}(\mathrm{AZ})_{2}\right]}
\end{gathered}+2 \mathrm{HCl}
$$


Table 3: Electronic spectral data $\left(\mathrm{cm}^{-1}\right)$ of $\mathrm{Hg}$ (II) mixed ligand complexes.

\begin{tabular}{||c|c|c||}
\hline Complex & $v_{\max }\left(\mathrm{cm}^{-1}\right)$ & Assignment \\
\hline \multirow{2}{*}[\mathrm{Hg}(\mathrm{HPTSC})_{2}(\mathrm{AZ})_{2}]{$\mathrm{Cl}_{2}$} & 25,778 & IL-charge transfer \\
& 33,958 & $\pi-\pi *$ transition \\
\hline \multirow{2}{*}[\mathrm{Hg}(\mathrm{HATSC})_{2}(\mathrm{AZ})_{2}]{$\mathrm{Cl}_{2}$} & 29,421 & IL-charge transfer \\
& 37,468 & $\pi-\pi *$ transition \\
\hline \multirow{2}{*}[\mathrm{Hg}(\mathrm{HFTSC})_{2}(\mathrm{AZ})_{2}]{$\mathrm{Cl}_{2}$} & 25,629 & IL-charge transfer \\
& 32,751 & $\pi-\pi *$ transition \\
\hline
\end{tabular}

Table 4: Thermal decomposition data of $\mathrm{Hg}$ (II) mixed ligand complexes in dynamic air.

\begin{tabular}{||c|c|c|c|c|c|}
\hline \multirow{2}{*}{ Complex } & \multirow{2}{*}{ Step } & \multicolumn{3}{|c|}{ TG/DTG } & Mass loss \\
\cline { 3 - 5 } & & $\mathrm{T}_{\mathrm{i}}{ }^{\circ} \mathrm{C}$ & $\mathrm{T}_{\mathrm{m}} /{ }^{\circ} \mathrm{C}$ & $\mathrm{T}_{\mathrm{f}} /{ }^{\circ} \mathrm{C}$ & $(\%)$ \\
\hline & $1^{\underline{\text { st }}}$ & 118 & 251 & 274 & 9.1 \\
{$\left[\mathrm{Hg}(\mathrm{HPTSC})_{2}(\mathrm{AZ})_{2}\right] \mathrm{Cl}_{2}$} & $2^{\text {nd }}$ & 276 & 314 & 425 & 11.4 \\
& $3^{\text {rd }}$ & 426 & 660 & 750 & 44.7 \\
\hline & $1^{\text {st }}$ & 140 & 248 & 277 & 8.4 \\
{$\left[\mathrm{Hg}(\mathrm{HATSC})_{2}(\mathrm{AZ})_{2}\right] \mathrm{Cl}_{2}$} & $2^{\text {nd }}$ & 287 & 308 & 409 & 12.2 \\
& $3^{\text {rd }}$ & 410 & 587 & 683 & 47.9 \\
\hline & $1^{\text {st }}$ & 124 & 268 & 281 & 8.7 \\
& $2^{\text {nd }}$ & 286 & 334 & 475 & 13.3 \\
& $3^{\text {rd }}$ & 476 & 671 & 750 & 39.1 \\
\hline
\end{tabular}

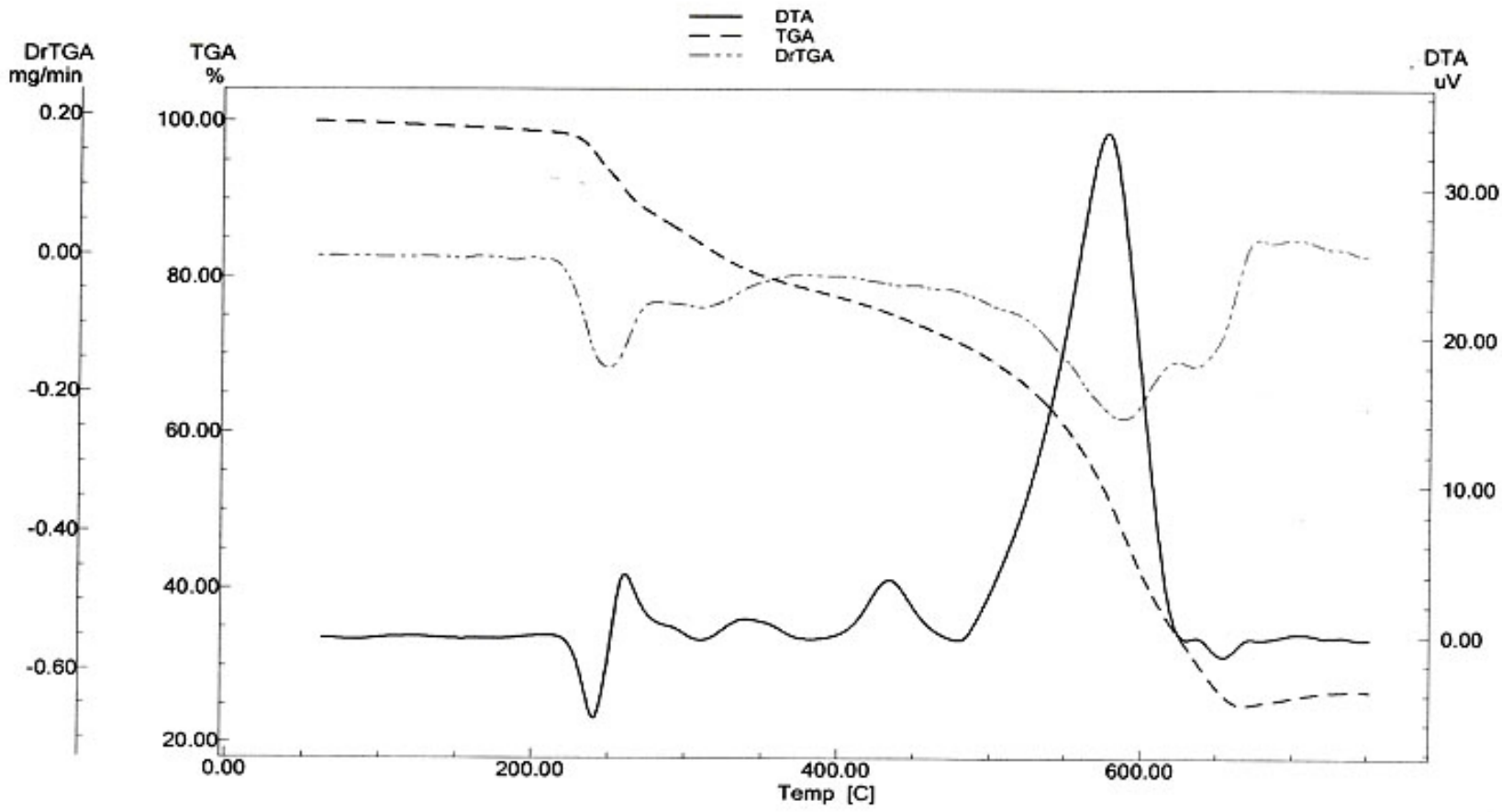

Fig. 3: TG, DTG and DTA thermograms of $\left[\mathrm{Hg}(\operatorname{HATSC})_{2}(\mathrm{AZ})_{2}\right] \mathrm{Cl}_{2}$. 
The second mass loss corresponds to the expulsion of one AZ molecule (calc. 11.3\%, found $12.2 \%$ ) (DTG peak at $308^{\circ} \mathrm{C}$ ). This step is marked on the DTA curve by an exothermic effect at $339^{\circ} \mathrm{C}$. The third mass loss $(47.9 \%)$ is indicated on the DTG curve as two peaks at 587 and $634^{\circ} \mathrm{C}$, with an exothermic effect at $579^{\circ} \mathrm{C}$ and an endothermic effect at $654^{\circ} \mathrm{C}$ in the DTA trace. The third mass loss represents the decomposition of 2(ATSC) and AZ molecules (calc. $46.9 \%$, found $47.9 \%$ ). The mass loss at $682^{\circ} \mathrm{C}$ indicates that the left stable residue is $\mathrm{HgO}$ (calc. 31.6\%, found $31.5 \%$ ) (equations 3,4 ).

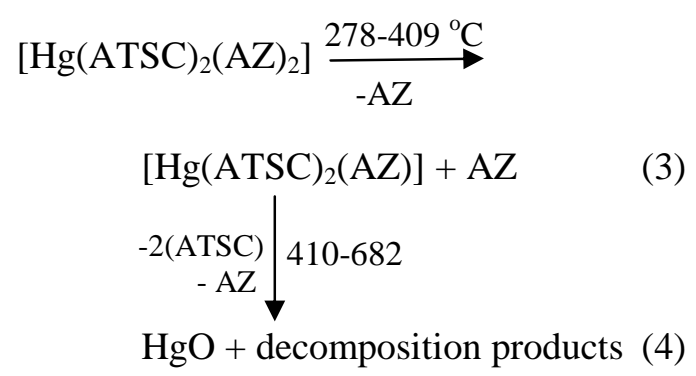

\section{b- Kinetic analysis}

Nonisothermal kinetic analyses for the thermal decomposition of the complexes were carried out by the application of two different procedures, namely the Coats-Redfern ${ }^{42}$ and Howowitz-Metzger ${ }^{43}$ equations. The kinetic parameters were evaluated only for clear-cut and nonoverlapping stages. The thermal data and kinetic parameters of the thermal decomposition of the complexes are included in Table 5. The activation energies in general are relatively low, indicating the low thermal stability of the complexes.
According to Cordes ${ }^{44}$, Shannon ${ }^{45}$ and Aly et $a l^{46}$, the frequency factor $\mathrm{Z}$ is related to the freedom degree of the activated complex and may vary between $10^{5} \mathrm{~s}^{-1}$ and $10^{18} \mathrm{~s}^{-1}$. Small values are often associated with a rigid activated complex, without degree of freedom, while high values may be correlated with a flexible activated complex. The $\mathrm{Z}$ values for the the first decomposition step of the complexes $\left[\mathrm{Hg}(\mathrm{HPTSC})_{2}(\mathrm{AZ})_{2}\right] \mathrm{Cl}_{2} \quad$ and $\left[\mathrm{Hg}(\mathrm{HATSC})_{2}(\mathrm{AZ})_{2}\right] \mathrm{Cl}_{2}$ are $10^{4} \mathrm{~s}^{-1}$ and $10^{8} \mathrm{~s}^{-1}$, respectively (Coats-Redfern equation). This means that the latter complex has more freedom or less rigidity than the first one.

Based on the above results of elemental analysis, I.R. \& electronic spectra, molar conductance and thermal analyses, the structures of $\mathrm{Hg}$ (II) mixed ligand complexes are proposed and given in Figure 4.

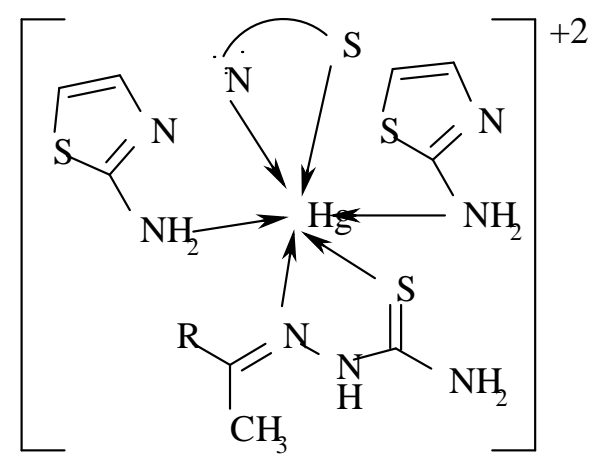

where ${ }_{\mathrm{N}}^{\mathrm{S}}=$ thiosemicarbazone ligand<smiles>C[R]=Cc1cccnc1C</smiles>

Fig. 4: Suggested structure of $\mathrm{Hg}(\mathrm{II})$ mixed ligand complexes. 
Table 5: Kinetic parameters for the thermal decomposition of $\mathrm{Hg}(\mathrm{II})$ mixed ligand complexes using non- mechanistic equations in dynamic air.

\begin{tabular}{|c|c|c|c|c|c|c|c|c|c|}
\hline \multirow{2}{*}{ Compound } & \multirow{2}{*}{ Step } & \multicolumn{4}{|c|}{ Coats-Redfern equation } & \multicolumn{4}{|c|}{ Horowitz-Metzger equation } \\
\hline & & $\mathrm{n}$ & $r$ & $\mathrm{E}$ & $\mathrm{Z}$ & $\mathrm{n}$ & $r$ & $\mathrm{E}$ & $\mathrm{Z}$ \\
\hline \multirow{6}{*}{$\begin{array}{c}{\left[\mathrm{Hg}(\mathrm{HPTSC})_{2}\right.} \\
\left.(\mathrm{AZ})_{2}\right] \\
\mathrm{Cl}_{2}\end{array}$} & \multirow{6}{*}{$1^{\mathrm{st}}$} & 0.00 & 0.9989 & 107.1 & $2.01 \times 10^{6}$ & 0.00 & 0.9987 & 103.1 & $2.26 \times 10^{6}$ \\
\hline & & 0.33 & 0.9997 & 145.2 & $1.12 \times 10^{8}$ & 0.33 & 0.9975 & 135.1 & $2.23 \times 10^{8}$ \\
\hline & & 0.50 & 0.9998 & 187.1 & $3.63 \times 10^{10}$ & 0.50 & 0.9998 & 196.9 & $2.85 \times 10^{10}$ \\
\hline & & 0.66 & 0.9999 & 211.1 & $3.71 \times 10^{11}$ & 0.66 & 0.9943 & 213.9 & $1.68 \times 10^{12}$ \\
\hline & & 1.00 & 1 & 246.2 & $3.52 \times 10^{13}$ & 1.00 & 0.9999 & 244.1 & $4.68 \times 10^{14}$ \\
\hline & & 2.00 & 0.9988 & 281.7 & $1.32 \times 10^{18}$ & 2.00 & $\overline{0.9972}$ & 278.8 & $5.19 \times 10^{18}$ \\
\hline \multirow{6}{*}{$\begin{array}{c}{\left[\mathrm{Hg}(\mathrm{HATSC})_{2}\right.} \\
\left.(\mathrm{AZ})_{2}\right] \\
\mathrm{Cl}_{2}\end{array}$} & \multirow{6}{*}{$1^{\mathrm{st}}$} & 0.00 & 0.9948 & 106.0 & $1.30 \times 10^{8}$ & 0.00 & 0.9949 & 105.3 & $2.36 \times 10^{8}$ \\
\hline & & 0.33 & 0.9967 & 121.3 & $6.16 \times 10^{9}$ & 0.33 & 0.9964 & 118.8 & $1.53 \times 10^{10}$ \\
\hline & & 0.50 & 0.9998 & 156.4 & $2.52 \times 10^{13}$ & 0.50 & 0.9990 & 158.3 & $4.32 \times 10^{14}$ \\
\hline & & 0.66 & $\underline{0.9999}$ & 163.6 & $1.65 \times 10^{14}$ & 0.66 & $\underline{0.9999}$ & 166.7 & $1.16 \times 10^{15}$ \\
\hline & & 1.00 & $\overline{0.9992}$ & 184.2 & $9.35 \times 10^{15}$ & 1.00 & $\overline{0.9992}$ & 180.4 & $9.84 \times 10^{16}$ \\
\hline & & 2.00 & 0.9997 & 242.5 & $3.90 \times 10^{19}$ & 2.00 & 0.9997 & 237.9 & $1.39 \times 10^{19}$ \\
\hline \multirow{6}{*}{$\begin{array}{c}{\left[\mathrm{Hg}(\mathrm{HFTSC})_{2}\right.} \\
\left.(\mathrm{AZ})_{2}\right] \\
\mathrm{Cl}_{2}\end{array}$} & \multirow{6}{*}{$1^{\mathrm{st}}$} & 0.00 & 0.9988 & 101.4 & $2.34 \mathrm{x}$ & 0.00 & 0.9991 & 100.3 & $3.64 \times 10^{7}$ \\
\hline & & 0.33 & 0.9989 & 111.7 & $4.12 \times 10^{8}$ & 0.33 & 0.9988 & 114.3 & $4.35 \times 10^{9}$ \\
\hline & & 0.50 & 0.9997 & 149.3 & $3.75 \times 10^{11}$ & 0.50 & 0.9992 & 151.8 & $2.31 \times 10^{12}$ \\
\hline & & 0.66 & $\underline{1}$ & 164.8 & $2.17 \times 10^{14}$ & 0.66 & 0.9999 & 161.2 & $1.69 \times 10^{15}$ \\
\hline & & 1.00 & 0.9993 & 179.4 & $6.54 \times 10^{17}$ & 1.00 & 0.9997 & 181.6 & $4.44 \times 10^{18}$ \\
\hline & & 2.00 & 1 & 233.6 & $1.92 \times 10^{19}$ & 2.00 & $\underline{0.9999}$ & 234.9 & $3.689 \times 10^{19}$ \\
\hline
\end{tabular}

$\mathrm{E}$ in $\mathrm{kJ} \mathrm{mol}^{-1} ; \mathrm{Z}_{\text {in s}}{ }^{-1}$ underlined $r$ in all tables represent the best fit values of $\mathrm{n}, \mathrm{E}$ and $\mathrm{Z}$.

$\mathrm{n}=$ order of the decomposition reaction

$\mathrm{r}=$ correlation coefficient

$\mathrm{E}=$ activation energy of decomposition

$\mathrm{Z}=$ preexponential factor

\section{REFRENCES}

1- A. Mohsen, M. E. Omar, I. M. Labouta, M. G. Kasem and J. Boudais, J. Pharm. Sci., 72, 1226 (1983).

2- M. J. M. Campbell, Coord. Chem. Rev., 15, 279 (1975).

3- S. Padye and G. B. Kauffmann, ibid., 63, 127 (1985).

4- D. X. West, S. B. Padye and P. B. Sonawane, Struct. Bond., 76, 1 (1991).

5- D. L. Klayman, J. F. Bartosecich, T. S. Grinffin C. J. Mason and J. P. Scoveill, J. Med. Chem., 22, 885 (1979).

6- E. J. Blanz and F. A. French, Cancer Res., 28, 2419 (1968).

7- M. C. Miller, C. N. Stineman, J. R. Vance, D.X. West and I. M. Hall, Anticancer Res., 18, 4131 (1998).

8- M. C. Miller, C. N. Stineman, J. R. Vance, D. X. West and I. M. Hall, Appl. Organomet. Chem., 13, 9 (1999).
9- J. P. Scovill, D. L. Klayman, C. Lambros, G. E. Childs, W. Antholing and D. H. Petering, J. Med. Chem., 27, 87 (1984).

10- A. A. El-Asmy, O. A. El-Gammal and H. S. Saleh, Spectrochim. Acta, Part A, 71, 39 (2008).

11- A. I. Matesanz, J. M. Perez, P. Navarro, J. M. Moreno, E. Colacio and P. Souza, J. Inorg. Biochem., 76, 29 (1999).

12- W. J. Geary, Coord. Chem. Rev., 7, 81 (1971).

13- M. Mohan, P. Sharma and M. Kumar, Inorg. Chim. Acta., 125, 9 (1986).

14- S. Chandra and L. K. Gupta, Spectrochim. Acta., Part A, 61, 269 (2005).

15- E. Jouad, G. Larcher, M. Allain, A. Riou, G. M. Bouet, M. A. Khan and X. D. Thanh, J. Inorg. Biochem., 86, 565 (2001).

16- M. J. M. Campbell, Coord. Chem. Rev., 15, 279 (1975).

17- V. S. Maliyeckal, R. P. Kurup and M. Nethaji, Polyhedron, 26, 3097 (2007).

18- S. Halder, R. J. Butcher and S. Bhattacharya, ibid., 26, 2741 (2007). 
19- S. Chandra and A. Kumar, Spectrochim. Acta., Part A, 67, 697 (2007).

20- S. V. Kolotilov, O. Cador, S. Golhen, O. Shvets, V. G. Ilyin, V. V. Pavlishchuk and L. Ouahab, Inorg. Chim. Acta., 360, 1883 (2007).

21- P. P. Singh and A. K. Srivastava, Aust. J. Chem., 27, 509 (1974).

22- S. Chandra and A. Kumar, Spectrochim. Acta., Part A, 66, 1347 (2007).

23- E. B. Seena and M. R. P. Kurup, Polyhedron, 26, 829 (2007).

24- P. F. Rapheal, E. Manoj, M. R. P. Kurup and E. Suresh, ibid., 26, 607 (2007).

25- V. Philip, V. Suni, M. R. P. Kurup and M. Nethaji, ibid., 25, 1931 (2006).

26- M. Joseph, A. Sreekanth, V. Suni and M. R. P. Kurup, Spectrochim. Acta., Part A, 64, 637 (2006).

27- V. Philip, V. Suni, M. R. P. Kurup and M. Nethaji, ibid., Part A, 64, 171 (2006).

28- D. Mishra, S. Naskar, M. G. B. Drew and S. K. Chattopadhyay, Inorg. Chim. Acta., 359, 585 (2006).

29- M. Joseph, M. Kuriakose, M. R. P. Kurup, E. Suresh, A. Kishore and S. G. Bhat, Polyhedron, 25, 61 (2006).

30- S. Chandra and U. Kumar, Spectrochim. Acta., Part A, 62, 940 (2005).

31- S. Chandra and L. K. Gupta, ibid., Part A, 62, 1089 (2005).

32- S. Chandra and L. K. Gupta, ibid., Part A, 61, 2549 (2005).

33- E. Bermejo, R. Carballo, A. Castineiras, R. Domnguez, C. M.- Mossmer, J. Strahle and D.X. West, Polyhedron, 18, 3695 (1999).
34- D. K.-Demertzi, A. Domopoulou, M. A. Demertzis, A. Papageorgiou and D. X. West, ibid., 16, 3625 (1997).

35- D. K.-Demertzi, C. Vidjeluc, M. A. Demertzis, E. Siapi and T. Mavromoustakos, Thermochim. Acta., 424, 53 (2004).

36- D. X. West, I. S. Billeh, J. P. Jasinski, J. M. Jasinski and R. J. Butcher, Transition Met. Chem., 23, 209 (1998).

37- D. X. West, J. S. Ives, J. Krejci, M. Salberg, T. L. Zumbahlen, G. Bain, A. Liberta, J.V. Martinez, S.H. Ortiz and R. Toscano, Polyhedron, 14, 2189 (1995).

38- D. Kovala-Demertzi, J. R. Miller, N. Kourkoumelis, S. K. Hadjikakou and M.

A. Demertzis, ibid., 18, 1005 (1999).

39- D. Kovala-Demertzi, A. Domopoulou, M. A. Demertzis, A. Papageorgiou and D. X. West, ibid., 16, 3625 (1997).

40- D. K.-Demertzi, A. Domopoulou, M. A. Demertzis, J. V.-Martnez, S. H.-Ortega, G. E.-Perez, D. X. West, M. M. Salberg, G. A. Bain and P. D. Bloom, ibid., 15, 2587 (1996).

41- M. Mikuriya, H. Okawa and S. Kida, Inorg. Chim. Acta., 34, 13 (1979).

42- A. W. Coats and J. P. Redfern, Nature, 20, 68 (1964).

43- H. H. Horowitz and G. Metzger, Anal. Chem., 35, 1464 (1963).

44- H. F. Cordes., J. Phys. Chem., 72, 2135 (1968).

45- B. R. Shannon., Trans. Faraday Soc., 60, 1902 (1964).

46- A. A. M. Aly, I. M. A. Awad, M. Abd ElMottaleb and K. Abd El-aal, Chem. Pap., 60, 143 (2006). 